\title{
Avaliação qualitativa de ambiência num Centro de Atenção Psicossocial
}

\section{Qualitative assessment of the environment in a Psychosocial Care Center}

LucianePrado Kantorski ${ }^{1}$

Valéria Cristina Christello Coimbra ${ }^{1}$

Emília $N$ alva Ferreira da Silva ${ }^{1}$

Ariane da Cruz Guedes ${ }^{1}$

Jandro M oraes Cortes ${ }^{1}$

Fernanda dos Santos ${ }^{1}$

Abstract Thisstudy is based on a cross-section of the study of Psychosocial Care Center (Caps) in the South of Brazil. O bjective: to conduct a qualitative assessment of the structure, in terms of environment, of a Capsin the interior of the State of Rio Grande do Sul. A casestudy was conducted on the Caps in Alegrete (RS) based on a fourthgeneration, constructivist and responsive assessment using a hermeneutic-dialectic approach. The data collection instruments were semi-structured interviews with a team (26), users (11), and family members (14), defined as interest groups to make up the hermeneutic-dialectic circle and field observation (390 hours) establishing prior ethnography. The structure of the Alegrete Caps was a strong aspect in the environmental evaluation. The lack of human and material resources does not interfere directly in user satisfaction with the environment.

Keywords Psychiatric Reform, Psychosocial Care Center, Assessment of services, Environment
Resumo Esteestudo consisteem recorte do estudo dos Centros de Assistência Psicossocial (Caps) do Sul do Brasil. 0 objetivo é avaliar qualitativamente a estrutura, através da ambiência, de um Caps do interior do Rio Grande do Sul. Foi realizado um estudo de caso do Caps de Alegrete (RS), fundamentado numa avaliação de quarta geração, construtivista, responsiva e com abordagem hermenêutico-dialética. Os instrumentos de coleta de dadosforam entrevistas semiestruturadas com equipe (26), usuários (11) e familiares (14), definidos como grupos de interessepara compor o círculo hermenêutico-dialético e a observação de campo (390 horas) configurando-se numa etnografia prévia. A estrutura do Caps A legrete foi um aspecto fortena avaliação da ambiência. A falta derecursos humanos e materiais não interfere diretamente na satisfação dos usuários com a ambiência. Palavras-chave Reforma Psiquiátrica, Centro de Atenção Psicossocial, Avaliação de serviços, Ambiência 
Introdução

0 presente artigo consiste num recorte da pesquisa "Avaliação dos Caps da Região Sul do Brasil", queficou conhecida como CapSul etevecomo objetivo avaliar os Centros de A tenção Psicossocial (I e II) da Região Sul (Rio Grande do Sul, Santa Catarina e Paraná) do Brasil. Subdividiuse em estudo quantitativo e qualitativo, como se verá a seguir.

O Estudo de Avaliação Quantitativa de Centros de Atenção Psicossocial realizou uma abordagem epidemiológica de avaliação de estrutura, processo e resultado com base em Donabedian ${ }^{1}$. 0 estudo quantitativo da qualidade de Atenção em Saúde M ental da Região Sul foi desenvolvido através de três subestudos complementares: estudo descritivo das características da estrutura das unidades de atendimento; estudo descritivo do processo de trabalho e organização da Atenção em Saúde dos Caps da Região Sul; estudo transversal de avaliação dos resultados da Atenção em Saúde M ental da Região Sul. Para a descrição da estrutura e do processo foram incluídos 30 Caps (I ell) sorteados de forma al eatória erespeitando a proporção dedistribuição deCaps em cada estado da Região Sul e obtidos os questionários de trinta coordenadores e 454 trabaIhadores. No estudo transversal de resultados, a amostra proposta foi de quarenta usuários e quarenta familiares em cada um dos trinta Caps I e II da Região Sul do Brasil (três do Paraná, nove de Santa Catarina e 18 do Rio Grande do Sul), totalizando na prática 1.168 usuários e 937 familiares, considerando as perdas ocorridas.

O Estudo deAvaliação Qualitativa de Centros de Atenção Psicossocial da Região Sul do Brasil utilizou-se da avaliação de quarta geração - construtivista, responsiva e com abordagem hermenêutico-dialética. A Avaliação deQuarta Geração, desenvolvida por Guba e Lincoln ${ }^{2-4}$ e adaptada por Wetzel ${ }^{5}$, foi norteadora do processo teóricometodológico da pesquisa, e os instrumentos de coleta de dados foram entrevistas com trabalhadores, usuários e familiares (definidos como grupos de interesse para compor o círculo hermenêutico-dialético) eobservação de campo (configurando-se numa etnografia prévia).

A aplicação prática da Avaliação Qualitativa de Quarta Geração aconteceu por meio de:

1 - Contato com o campo: contato com a equipe do serviço, sendo apresentada ediscutida a proposta da pesquisa;

2 - Identificação dos stakeholders ou grupos de interesse: esses grupos são formados por pes- soas com características comuns que têm al gum interesse no desempenho, no produto ou no impacto do objeto da avaliação; foram incluídos na pesquisa três grupos de interesse: equipe, usuários e familiares;

3 - Desenvolvimento e ampliação das construções conjuntas: a aplicação do círculo hermenêutico-dialético;

4 - Apresentação das questões para os grupos de interesse: consistiu na organização das construções do grupo, para que eles pudessem ter a oportunidade devalidá-las, ou seja, modificá-las ou afirmar a sua credibilidade.

Em uma escolha intencional, foram selecionados cinco Caps, tendo como parâmetro os dados obtidos na etapa de avaliação quantitativa, referentes à estrutura, ao processo e sua adequação às normas definidas pela Portaria $\mathrm{n}$ 0 336/ 2002. Foram também considerados o tempo de funcionamento e experiência do serviço e a disponibilidade dos grupos de interesse em aderirem à proposta.

A etapa qualitativa do estudo de avaliação Capsul concentrou-se em Centros de Atenção Psicossocial I ell, de cinco municípios da Região Sul do país, desenvolvida na forma de estudo de caso $^{6}$, sendo realizada observação de campo (entre 282 e 650 horas em cada campo) e entrevistas que compuseram o círculo hermenêutico- dialético. Foram entrevistados entre 10 e 13 usuários em cada campo (totalizando 57 usuários), entre 10 e 14 familiares em cada campo (totalizando sessenta familiares), e entre 10 e 26 trabalhadores em cada campo (totalizando 88 trabal hadores).

A pós a coleta dos dados brutos da entrevista, foi realizada uma análise prévia com o objetivo de estruturar as oficinas de validação das informações obtidas dos diferentes grupos de interesses envolvidos. Então os dados refinados foram apresentados para os respectivos grupos, para que tivessem acesso à totalidade das informações e a oportunidade de modificá-las ou afirmar a sua credibilidade. A negociação foi realizada mediante a utilização da técnica grupal, sendo convidados todos os entrevistados de determinado círculo.

A partir das unidades de informação extraídas das falas emergiram marcadores de avaliação que pautaram as análises. Estes seguiram uma orientação teórica já utilizada na etapa da avaliação quantitativa da pesquisa CapSul, enfocando a estrutura, o processo e os resultados (conforme Donabedian ${ }^{1}$ ). A partir desta orientação teórica mais ampla, foram desdobrados os seguintes marcadores: estrutura - ambiência; processo - 
atividades como suporte terapêutico, equipe, características e organização do processo de trabaIho, plasticidade do serviço, inserção da família; resultado - resultado da atenção psicossocial.

Por marcadores denominou-se determinada categoria que foi abstraída a partir dos dados empíricos e que tem a capacidade explicativa de indicar determinado parâmetro deavaliação. Por exemplo, no marcador interno de estrutura que indicou aspectos qualitativos a serem avaliados foi a ambiência, abordada neste artigo, a partir do estudo de caso do Caps de Alegrete (RS).

A ambiência refere-se ao tratamento dado ao espaço físico entendido como espaço social, profissional e de relações interpessoais que proporciona atenção acolhedora, resolutiva e humana. A ambiência na arquitetura dos espaços da saúdevai além da composição técnica, si mples e formal dos ambientes, e considera as situações que são construídas. 0 conceito de ambiência segue três eixos: o espaço que visa à confortabilidade, foca a privacidade eindividualidade dos sujeitos envolvidos, valorizando o ambiente (cor, cheiro, som, iluminação, dentre outros) e garantindo conforto aos usuários e trabalhadores; o espaço que possibilita a subjetividade; o espaço que favorece a otimização de recursos, 0 atendimento humanizado eacolhedor. Sobre esses eixos, neste estudo foram privilegiados na análise os dois primeiros (conforto e subjetividade) ${ }^{7}$.

0 conceito de ambiência preconizado na política de humanização do M inistério da Saúde foi incorporado à saúde mental e, particularmente neste estudo, referindo-se a aspectos relacionados à estrutura física e material do Caps, considerando a ambiência como o espaço social, profissional e relacional, enfocando especialmente a dimensão qualitativa que permite operar em um serviço em que a cor, o conforto, a privacidade, 0 sentir-se acolhido e seguro e a oferta de espaços de expressão desubjetividades são potencial mente decisivos no processo de atenção psicossocial.

Os Centros de Atenção Psicossocial são incorporados como política pública desaúdemental de referência para todo o país, inscrevendo-se em um contexto que pretende desenvolver novas tecnologias em saúde mental que respeitem o usuário no seu direito de cidadania e que se diferenciem do modelo manicomial excludente dominanter.

Os Caps surgem como uma possibilidade de assistência em uma proposta mais ampla deuma rede de cuidados em saúde mental: a proposta de criação de um sistema de saúde que contemplea abordagem integral dos indivíduos edesuas famílias.
0 presente estudo justifica-se, principalmente, pela premência de se olhar para essas novas modalidades públicas de atenção, que estão sendo abertas no país, buscando-se avaliar essas ações. Seu objetivo é avaliar qualitativamente a estrutura, através da ambiência, de um Caps do interior do Rio Grande do Sul.

\section{M etodologia}

N este artigo, abordamos o estudo de caso do Caps de Alegrete (RS) fundamentado numa avaliação de quarta geração, construtivista, responsiva e com abordagem hermenêutico-dialética. Os instrumentos de coleta de dados foram entrevistas semiestruturadas com equipe(26), usuários (11) efamiliares (14), definidos como grupos de interesse para compor o círculo hermenêutico-dialético e a observação de campo ( 390 horas), configurando-se numa etnografia prévia. A avaliação qualitativa do Caps de Alegrete fundamentou-se numa avaliação de quarta geração, construtivista, responsiva e com abordagem hermenêutico-dialética.

Após a coleta de dados, estes foram organizados e transcreveram-se na íntegra observações de campo e entrevistas, dando-se início à fase de organização e análise dos dados. N esse espaço, enfocamos a avaliação qualitativa da estrutura do Caps centrada nos aspectos pertinentes à ambiência incluindo estrutura física, material, alimentação, segurança e transporte. O Projeto de Pesquisa de Avaliação dos Caps da Região Sul do Brasil foi apreciado e aprovado pelo Comitê de Ética e Pesquisa da Faculdade de M edicina da Universidade Federal de Pelotas. Todos os entrevistados concordaram em participar da pesquisa mediante a assinatura de consentimento livre e esclarecido.

No texto, os usuários são identificados pela letra " $U$ ", os familiares pela letra " $F$ " e a equipe pela letra " $E$ ", seguida do número correspondenteà entrevista.

0 processo de negociação com os grupos de interesse ocorreu em data e horário previamente acordado, havendo um comparecimento da maioria dos entrevistados. Foi produzido um material impresso com a síntese do material das entrevistas de cada grupo de interesse, a cada membro do grupo foi entregue uma cópia, e realizou-se por um pesquisador da equipe uma apresentação oral (com auxílio do material organizado em Power Point). Cada aspecto evidenciado nas entrevistas foi discutido, validado enegociado como 
eixo prioritário da avaliação do Caps a partir da construção do grupo de interesse.

\section{Resultados ediscussão}

\section{Avaliação qualitativa da ambiência no Caps de Al egrete}

0 município de Alegrete localiza-se na fronteira oeste do Rio Grande do Sul, a 506 quilômetros de distância da capital, Porto Alegre. Possui um total de 89.144 habitantes, sendo que destes 44.828 são do sexo feminino e 44.316 pertencem ao sexo masculino?.

A base da economia está centrada na agricultura e na pecuária e apresenta uma área total de 45.000 hectares de lavouras de arroz; rebanho bovino: 536.536 cabeças; produção de leite: 15.269 litros; e rebanho ovino: 423.446 cabeças $^{10}$.

A presenta um total de 32 estabelecimentos de saúde, dos quais 22 pertencem ao sistema público de saúde e apenas três estabelecimentos de saúde no âmbito do Sistemaú nico deSaúde(SUS), com atendimento de emergência em psiquiatria. Em 2005 teve 1.056 nascidos vivos, com uma taxa bruta de natalidade de $12 \%$ no mesmo ano, e em relação à mortal idade apresentou 17 mortes infantis. Em 2006 apresentou 233 internações em psiquiatria, correspondendo a 3,8\% das internações dentre as demais especialidades. N essa cidade, as maiores causas de mortalidade se dão por doenças do aparelho circulatório, seguidas por neoplasias e doenças do aparel ho respiratório11.

O serviço de saúdemental tem início em 1989, numa época em que havia falta de recursos e as pessoas que trabalhavam na saúde mental eram designadas para esta área por motivo de punição ou porque não tinham um bom desempe nho em outros lugares. Com o passar do tempo, o serviço foi se estruturando e ampliando seus espaços na sociedade com propagandas na mídia, participação em eventos sociais, articulações políticas, melhorias nas condições do serviço e implantação do residencial terapêutico.

A rede de saúde mental do município deAlegrete compõe-se de Caps II, Capsi, Caps ad (em formação), residência terapêutica eleitos psiquiátricos em hospital geral.

A equipe profissional compõe-se de dois mé dicos, sendo um psiquiatra e outro clínico, duas enfermeiras, quatro técnicos de enfermagem, um assistente social, seis psicólogos, um terapeuta ocupacional, sete oficineiros (seis são estagiários pela Prefeitura, com contratos de duração de dois anos) que têm formação em educação física e pedagogia; possui ainda três profissionais na recepção, uma cozinheira e um motorista.

0 processo de desinstitucionalização consiste num processo prático de desconstrução e de reinvenção simultânea de novas realidades, que são construídas pelos atores sociais do processo de mudança ${ }^{12,13}$. Portanto, a reinvenção dos espaços de cuidado não é meramente coadjuvante do processo de mudança. $O$ fato de 0 Caps de Alegrete se apresentar como uma estrutura flexível, que não lembra a estrutura rígida do manicômio (representada em muros, grades, corredores frios, espaços impessoais), que não reproduz aquele cheiro, aquela ausência de cores, re flete em parte um processo de desconstrução, gerador de um outro espaço.

Entendemos quea questão da ambiência consiste num dos aspectos fortes na avaliação do Caps de Alegrete. 0 prédio de dois andares foi reformado para abrigar o serviço e encontra-se em condições de conservação ótimas, sendo bem arejado, com várias salas personalizadas, decoradas, pintadas em cores diferentes e espelhadas.

A estrutura básica é herança de um antigo hospital de tuberculosos. É um prédio bem amplo, com várias salas de atendimentos, identificadas por cores (sala verde, sala amarela, dentre outras). Existem duas salas grandes, sendo que uma é destinada à real ização de oficinas e outra a grupos ereuniões de equipe. No andar inferior há uma horta, um lugar onde estão organizando um jardim, uma espécie de quadra de futebol, uns banquinhos para os pacientes tomarem sol, e também uma ampla sala onde ocorrem oficinas de alfabetização (dados coletados com base nas observações registradas em diário de campo).

A confortabilidade, a privacidade e a individualidade dos espaços no caso do Caps Alegrete são contemplados, considerando que a oficina de ioga, por exemplo, acontece numa sala lilás, que contém espelhos, colchonetes, música instrumental ambiente e incenso aromático.

$\mathrm{Na}$ avaliação do Caps de Alegrete, a ambiência é avaliada pelos grupos de interesse, considerando primeiramente 0 fato de 0 atendimento ser ágil e realizado em espaços agradáveis. Em contrapartida, a necessidade de ampliação do espaço físico também é mencionada.

Em relação ao espaço oferecido pelo Caps para as atividades, segundo 0 entendimento dos familiares eusuários, este poderia ser ampliado, criando sala de esportes, por exemplo, a fim de ofertar mais atividades recreativas. A equipedo Caps sentefalta de salas maiores para atender todos os usuários e 
também de mais profissionais, pois essas melhorias iriam garantir melhor atendimento.

Eu acho até que podia ampliar, fazer um salão, coisa para eles de esporte, isso seria legal. [ $F$ 6]

Para melhorar, a gente precisava de mais funcionários. Porquecada vez parece queestá aumentando maiso fluxo, está entrando mais gente, mais gente. [E 18]

Tem campo de futebol, se bem que podia meIhorar. Não só para quea pessoa tenha um serviço, mas para 0 usuário também ter mais atividades para ser tratado. [U 3]

No que se refereà alimentação, à higi ene e ao lazer, os usuários referem que a alimentação é de boa qualidade, há a possi bilidade de realizarem a higiene corporal no serviço e há espaços destinados ao lazer e à prática de atividade física. $\mathrm{Na}$ observação de campo, constatou-se que os usuários têm dois espaços de descanso para utilizarem após as refeições, uma sala com poltronas reclináveis, arejada, bastante confortável; outra sala ampla, com poltronas reclináveis e televisão, onde al guns assistem ao jornal e descansam.

Com relação ao almoço especificamente, ele foi terceirizado e é trazido por um restaurante que é conhecido como um dos melhores no município, o qual servepessoas demaior poder aquisitivo. Constata-se nas observações de campo e através dos depoimentos dos usuários que a alimentação é de ótima qualidade.

É boa a comida, comida derico, mesmo. [U 8]

Eu acho que a alimentação é ótima [...] 0 que a gente come aqui, dificilmente 0 pobre comeria todos os dias. É uma alimentação ótima. [U 11]

Num contexto histórico em que por longo pe ríodo os "loucos" foram excluídos do convívio social, do consumo de bens, da cultura e da arte, por exemplo, um serviço que se propõe a cuidar em liberdadeequearticuladiferentes recursos da comunidade, como o restaurante conhecido como "o melhor", requer um destaque com relação à produção de soluções criativas em condições nem sempre tão favoráveis. 0 Caps de Alegrete vinha num processo em que a elaboração do almoço no serviço estava em crise, pois os alimentos fornecidos não permitiam a elaboração de uma dieta adequa$\mathrm{da}$, o fornecimento era descontínuo e os embates com a gestão eram sucessivos. Considera-se que possa haver um questionamento sobre este tema, pois a elaboração do almoço no Caps poder-se-ia constituir em um processo terapêutico deintroduzir maisum componentede reabilitação para assumir as tarefas diárias da casa. No entanto, no Caps essa terceirização do almoço criou um diferencial importante, como componente de inclusão.
Outra questão levantada na avaliação diz respeito à higiene dos usuários. Num período anterior à coleta de dados da pesquisa, havia um funcionário responsável pelo acompanhamento da higienização dos usuários. No entanto, observou-se que isto foi rompido, havendo uma discussão na equipe sobre quem deveria se responsabilizar por essa tarefa. N esse período deindefinição, os usuários decidiam por conta própria sobre realizar ou não sua higiene pessoal, o que gerou uma série de reclamações.

Eu tomo banho, não fico sujo, mas eles estavam tomando banho, agora não sei se pararam. Eu não venho mais almoçar aqui, almoço em casa. Eles ficavam sempre tomando banho antes do almoço. Pegavam e levavam para o banheiro, pegavam xampu, pente, e quem não estava com a barba feita, fazia a barba para não chegar na hora da comida cabeludo. Asunhas, ol havam, cortavam, bem antes do almoço, não era depois, era antes. Tomavam banho para entrar no refeitório, para não ir sujo e fedorento. [U 8]

O espaço do Caps deve levar em conta características muito peculiares, incluindo as características da clientela queatendee as manifestações dos diferentes transtornos psíquicos. Como o Caps se propõe a ser um espaço de cuidado em liberdade, precisa permitir que as subjetividades se expressem, que o sofrimento semanifeste, mas precisa oferecer um local de cuidado adequado e com profissionais em condições de oferecer continência ao sofrimento do outro.

N essesentido, a presença ou ausência de profissionais no ambiente é evidenciada como um parâmetro qualitativo para se avaliar a ambiência. Familiares relatam que os usuários são observados o tempo todo em que estão no serviço; em contrapartida, outro familiar diz que poderia haver no Caps mais profissionais para ficarem supervisionando os pacientes no pátio. Poderia ter um profissional para garantir maior segurança para os usuários, até separar os pacientes mais críticos para que não ocorram agressões entre os usuários.

Sempre estão olhando para as pessoas. Eu cansei de estar ali quando fazia fisioterapia, e tem aquela assistente, que dá as fichas, aquela moça está sempre cuidando [...]. Acho que pode aumentar. Para uns está bom, para outros falta. 0 povo não pode dizer qual é o certo, então a Prefeitura pode aumentar essa parte, botar mais gente para fazer trabalhos para as pessoas. [F 12]

Eu já vi, às vezes com a minha mãe, ela ia estava muito bem, quando via, ela dava um tapão num lá. A cho que precisa de uma pessoa para ficar ali observando, conversando e estimulando. [F 10] 
Um problema enfrentado pelos profissionais do Capséa falta de materiais queviabilizem uma infraestrutura de atendimento nas situações de crise, impossibilitando um adequado funcionamento do serviço. A equipe do serviço diz que quando ocorre um surto faltam as medicações necessárias para o tratamento e que limitações na estrutura física do serviço também impedem o manejo adequado da situação.

Eu tenho dificuldade de usar atitudes medicamentosas de maneira mais sedativa. Com medicações injetáveis, eu não tenho muita estrutura para dar um apoio. Por exemplo, se a pessoa tiver uma parada cardíaca, respiratória, uma depressão respiratória que tenha. No momento que se faz um Valium injetável, para acalmar uma pessoa em agitação psicomotora, a gente tem muita dificuldade, a gente se priva e tenta fazer uma contenção mecânica. De uma certa forma a gente tem um bom relacionamento com o pessoal do Pronto Socorro M unicipal. Alguma atenção rápida [...] A gentefaz uma contenção, segura, tenta, na medida do possível, colocar na maca e levar para o Pronto Socorro para dar uma medicação de urgência. A gente não usa medicação deurgência em função disso, da nossa dificuldade de lidar com o risco. [E 25]

O Capséum serviço quese propõea cuidar de pessoas com transtornos severos e persistentes, conforme preconiza a Portaria no 336/2002 $2^{14}$. Especialmentea equipe traz a questão do déficit material, a necessidade de capacitação do pessoal e a inadequação do espaço para atender a situações de crise, as quais fazem parte do cotidiano de trabaIho de um serviço como o caps. Inegavelmente, esses aspectos interferem na ambiência, configurando-se em momentos em que esse espaço, de adequado, passa a revelar-se como inseguro.

A dificuldade em atender às situações de crise, especialmente quando envolvem risco de agressividade, é evidenciada em situações que se colocam no dia a dia do serviço, restritas ao espaço interno do Caps e em visitas domiciliares realizadas pelos trabalhadores. A equipe destaca que às vezes énecessário chamar a Brigada Militar para garantir a segurança. Alguns profissionais referem haver necessidade de um aprendizado sobre técnicas de manejo de agressividade para os funcionários do serviço, refutando essa prática de contar com a presença constante da Polícia. U ma alternativa explicitada pela equipe, duranteas entrevistas, eretomada na negociação consiste na contratação de mais funcionários do sexo masculino.

Tu vêque aqui não tem um homem. Não queo homem vá segurar, mas uma pessoa para conter. Eu me sinto insegura nessas situações. [E 12]
Eu diria do assunto é que na maioria são muIheres, entendeste? Falta às vezes a genteter 0 acompanhamento deum rapaz, deum cara mesmo para estar junto [...]. Eu acho quena parte da tarde faz falta de uma pessoa do sexo masculino. $N$ ão é que dê segurança a nós, équetem mais força, tem mais agilidade e dá respeito. Chega um gurizão e impõe respeito. [E 26]

$A$ atenção à crise consiste num dos aspectos mais estratégicos para um Caps, pois representa um momento de alta vulnerabilidade do sujeito e seus vínculos. $\mathrm{Na}$ concepção da psiquiatria tradicional, a noção de crise está ligada à disfunção, à ruptura com o princípio da realidade, à desorganização. As intervenções que decorrem dessa concepção visam à doença em si e suas manifestações, pretendem trazer para a realidade $o$ indivíduo, adaptá-lo à ordem social; visam suprimir alucinações e delírios, reorganizar o pensamento, enquadrar o comportamento. Para dar conta desta tarefa, dispõe da contenção mecânica, me dicamentosa, da eletroconvulsoterapia, ações voltadas à doença e suas manifestações ${ }^{15-17}$.

Em contraposição, no interior do modo psicossocial a crise é compreendida como resultado de um processo que envolve outras pessoas além do sujeito em sofrimento psíquico: a família, os vizinhos, os amigos, entre outros. Consiste num momento de diminuição do limiar de tolerância ou solidariedade, deprecariedadederecursosparatratar a pessoa em domicílio. Enfim, a crise conta com componentes coletivos e de determinação social além dos psicológicos, biológicos ou individuais ${ }^{18}$.

A capacitação para manejar a crise também consistiu em um ponto explorado na negociação como alternativa a ser mobilizada para suprir parte das dificuldades identificadas no processo avaliativo, com relação aos episódios de agressividade. A equipe revela uma contradição importante eaté um certo sofrimento ante o dilema de cuidar em liberdade e dispor de mecanismos de coerção tão representativos no imaginário social, como a Brigada M ilitar/Polícia. A fala a seguir problematiza esta situação:

Outra coisa que acho muito importante aqui em Alegrete, por exemplo: quando acontece esse tipo de coisa é chamada a Brigada. Não tem uma ambulância que venha até o local e leve essas pessoas que têm que ser medicadas, para se acalmarem na maioria das vezes. Esse momento que che ga os brigadianos, tu pode atéachar queéum pouco ingênuo isso aí, mas é incrível. No momento que chega o brigadiano para algemar e levar eu acho que aumentou um pouco mais a violência, é uma cena tão feia, tão feia. [E 17] 
O modo psicossocial implica mudanças na forma de pensar e acolher a pessoa em sofrimento psíquico, passando a compreendê-la a partir de sua existência-sofrimento, e não apenas do seu diagnóstico e dos sintomas apresentados. Os momentos de crises poderão ser acoIhidos efetivamente se concebidos como integrantes do modo como o sujeito se posiciona ante as situações conflitantes que 0 atravessam ${ }^{19}$.

Nesse sentido, torna-se imprescindível constituir espaçose modos deacolher a crisequecomportem as diferentes dimensões destes conflitos superando a visão individualizada, sintomática e reducionista da crise.

As diferentes alternativas apresentadas na negociação relativas a recursos materiais e humanos, assim como especificamente o investimento em capacitações ea inclusão de profissionais do sexo masculino na equipe, constituíramse em possíveis caminhos apontados no processo avaliativo.

Porém, subjetivamente outro componente da avaliação se fez tão importante quanto os anteriores; consistiu em utilizar o momento da entrevista no círculo hermenêutico-dialético e da negociação para problematizar posturas teóricas e práticas diante da construção de um cuidado psicossocial que vem sendo construído.
Um aspecto inter essante a ser destacado consiste na satisfação do trabalhador com o ambiente e tudo que o trabalho no Caps comporta, pois os limites de estrutura física e recursos humanos não implicam mecanicamente insatisfação; ao menos a equipe, de modo geral, manifestou em depoimentos durante o período das entrevistas e observação de campo uma importante satisfação com o trabalho que realiza, fator que contribui para qualificar a ambiência.

Gosto de vir todos os dias para o serviço, gosto de estar com a equipe, de trabalhar com o pessoal, o pessoal dá muita força. M uita força para os outros. [E 10].

Assim, apresentamos no Quadro 1 a avaliação da ambiência do Caps deA legrete(RS) sintetizada a partir da validação nos grupos de interesse.

\section{Consideraçõesfinais}

Com relação à ambiência, constatamos que os três grupos de interesse, usuários, familiares e equipe do Caps, avaliam a estrutura física, material, alimentação, segurança e transporte, enfatizando aspectos pertinentes à qualidade do espaço social, profissional e relacional proporcionado por um serviço que acolhe, faz vínculo, con-

Quadro 1. Avaliação da ambiência do Caps de Alegrete (RS).

\begin{tabular}{|c|c|c|c|}
\hline Estudo de caso & Familiares & Usuários & Equipe \\
\hline Caps Alegrete & $\begin{array}{l}\text { - Ambiente físico: } \\
\text { agradável; boa higiene } \\
\text { no local; poderia ser } \\
\text { ampliado, criar sala de } \\
\text { esportes; } \\
\text { - Alimentação: boa } \\
\text { qualidade; variedade; } \\
\text { - Equipe: necessidade de } \\
\text { mais profissionais para } \\
\text { supervisionar os } \\
\text { usuários; } \\
\text { - Apoio da Brigada } \\
\text { Militar: qualificar } \\
\text { pessoas da equipe para o } \\
\text { relacionamento com o } \\
\text { usuário e seus sintomas; } \\
\text { - Banheiro: faltam } \\
\text { toalhas; cada usuário } \\
\text { deve ter o seu sabonete; } \\
\text { - M edicação: às vezes } \\
\text { não há. }\end{array}$ & $\begin{array}{l}\text { - Ambiente físico: agradável; } \\
\text { poderia ser ampliado, criar sala } \\
\text { de esportes; há espaços para lazer } \\
\text { e prática de atividades físicas; } \\
\text { - Alimentação: proveniente de } \\
\text { um dos melhores restaurantes da } \\
\text { cidade; ótima qualidade; } \\
\text { - Higiene: há a possibilidade de } \\
\text { realizarem a higiene corporal no } \\
\text { serviço; decidem por conta } \\
\text { própria realizar ou não; } \\
\text { - Oficinas terapêuticas: alguns } \\
\text { usuários participam, gostam e } \\
\text { referem que não há falta de } \\
\text { material; outros dizem que a } \\
\text { quantidade de material é } \\
\text { insuficiente e que os oficineiros } \\
\text { não estão suficientemente } \\
\text { capacitados; } \\
\text { - Equipe: trata bem; sem } \\
\text { preconceitos. }\end{array}$ & $\begin{array}{l}\text { - Ambiente físico: falta } \\
\text { de salas maiores para } \\
\text { atender todos os } \\
\text { usuários; } \\
\text { - Equipe: falta de } \\
\text { pessoal; } \\
\text { - Situações de crise: } \\
\text { falta de materiais para } \\
\text { atendimento; } \\
\text { despreparo da equipe; } \\
\text { necessidade de } \\
\text { capacitação; há o auxílio } \\
\text { da Brigada M ilitar; } \\
\text { contratar mais } \\
\text { funcionários do sexo } \\
\text { masculino. }\end{array}$ \\
\hline
\end{tabular}


forta, se responsabiliza por pessoas em sofrimento psíquico.

Destacam que, de modo geral, a ambiência é favorecida no Caps, pois o princípio de que a liberdadeéterapêutica viabiliza uma gama deiniciativas nesse serviço a fim de tornar 0 ambiente confortável e acolhedor. 0 fato de o Caps deAlegrete contar com uma estrutura física, um prédio próprio, também influencia na ambiência, favorecendo a segurança e a estabilidade do serviço.

O Caps Alegrete obteve uma avaliação positiva da ambiência, pois a estrutura física e a subjetividade do serviço são respeitadas e valorizadas por todos os envolvidos no processo de fortalecimento dessa nova modalidade de Atenção em Saúde M ental.

Os limites apontados na avaliação estão especialmenterelacionados à falta dematerial para oficinas, falta de pessoal enecessidade de capacitação para atuar nas oficinas, para manejar a crise e se relacionar com o usuário.

O estudo de avaliação foi importante para evidenciar potencialidadeselimites da ambiência no Caps, seus resultados permitindo refletir sobre este marcador no contexto de outros serviços de saúde.

\section{Colaboradores}

LP Kantorski trabalhou na pesquisa, metodologia, coleta de dados, concepção e redação final; VCC Coimbra, ENF Silva, AC Guedes, JM Cortes e F Santos trabalharam na concepção e na redação final.

\section{Referencias}

1. Donabedian A. La calidad de la atención medica: definición y metodos de evaluación. M exico: Ediciones Cientificas La Prensa M edica M exicana, Ediciones Copilco; 1984.

2. Guba E, Lincoln Y. Effective evaluation: improving the usefulness of evaluation results through responsive naturalistic approaches. San Francisco: JosseyBass Publishers; 1985.

3. Guba E, Lincoln Y. Fourth generation evaluation. N ewbury Park: Sage Publications; 1989.

4. Guba E, Lincoln Y. Effective evalution. San Francisco: Jossey-Bass Publishers; 1998.

5. Wetzel C. Avaliação de serviços de Saúde M ental: a construção de um processo participativo [tese]. Ribeirão Preto: Escola de Enfermagem de Ribeirão Preto, Universidade de São Paulo; 2005.

6. Yin RK. Estudo de caso: planejamento e métodos. 3a ed. Porto Alegre: Bookman; 2005.

7. Brasil. Ministério da Saúde. Secretaria de Atenção à Saúde. Núcleo Técnico da Política Nacional de Humanização. Ambiência. 2ạ ed. Brasília: Ministério da Saúde; 2007.

8. Carvalho ALL, Amarante P. Avaliação de qualidade dos novos serviços de saúde mental: em busca de novos parâmetros. Saúde em Debate 1996; 52:74-82.

9. Brasil. Instituto Brasileiro de Geografia e Estatística (IBGE). [site na Internet]. 2007 [acessado 2007 jan 10]. Disponível em: http://www.ibge.gov.br/cidade sat/topwindow.htm

10. Brasil. Município de Alegrete. [site na Internet]. 2007 [acessado 2007 jan 4]. Disponível em: http:// www.daer.rs.gov.br/tab_dist.pdf

11. Brasil. Dados Alegrete geral - RS. Datasus. [site da Internet]. 2007 [acessado 2007 jan 7]. Disponível em: http://tabnet.datasus.gov.br/tabdata/cadernos/ RS/RS_Alegrete_Geral.xls
12. Amarante P. 0 homem e a serpente. Rio de Janeiro: Editora Fiocruz; 1996.

13. Rottelli F, Leonardis O, Mauri D. Desinstitucionalização, uma outra via: a reforma psiquiátrica italiana no contexto da Europa Ocidental e dos "países avançados". In: Nicácio F, organizador. Desinstitucionalização. São Paulo: Hucitec; 1990. p. 17-59.

14. Brasil. M inistério da Saúde. Secretaria Executiva. Legislação em Saúde M ental 1990-2004. 5a ed. Brasília: M inistério da Saúde; 2004.

15. CID 10. Classificação de transtornos mentais e de comportamento da CID-10: descrições clínicas e diretrizes diagnósticas. Porto Alegre: Artmed, OM S; 1983.

16. Costa JRA, Lima JV, Almeida PC. Stress no trabalho do enfermeiro. Rev Escola de Enfermagem da USP 2003; 37(3):63-71.

17. Carvalho NR, Costa II. Primeiras crises psicóticas: identificação de pródromos por pacientes e familiares. Psicologia Clínica 2008; 20(1):153-164.

18. Amarante P. Saúde M ental e atenção psicossocial. Rio de Janeiro: Editora Fiocruz; 2007.

19. Costa-Rosa A. O modo psicossocial: um paradigma das práticas substitutivas ao modo asilar. In: Amarante P, organizador. Ensaios: subjetividade, saúde mental, sociedade. Rio de Janeiro: Editora Fiocruz; 2000. p. 141-168.

Artigo apresentado em 13/04/2008

Aprovado em 09/02/2009

Versão final apresentada em 09/03/2009 